\title{
The professional burnout of teachers working with gifted students
}

\author{
Alexander Dmitrievich Golmenko ${ }^{1 *}$, Valentine Abavna Haptanova ${ }^{2}$, Vadim Pavlovich \\ Peskov $^{3}$, and Anatoly Yurievich Haptanov ${ }^{4}$ \\ ${ }^{1}$ Irkutsk state University, Pedagogical Institute Department of Psychodiagnostics and Practical \\ Psychology, Irkutsk, Russia \\ ${ }^{2}$ Irkutsk State Medical University, Department of Polyclinic Therapy and General Medical Practice, \\ Irkutsk, Russia \\ ${ }^{3}$ Moscow city university, Institute of Pedagogy and Psychology of Education, Department of \\ Psychology, Moscow, Russia \\ ${ }^{4}$ Irkutsk State Medical University, Department of Therapeutic Dentistry, Irkutsk, Russia
}

\begin{abstract}
Since 2014, scholars have been studying the professional burnout of medical workers following the order of health care. In 2017, the authors of the article began to analyze the causes of burnout in teachers, including those who work with gifted children. The study of burnout is a socially significant task as the high-level burnout of doctors and teachers leads to a decrease in the quality of work, staff turnover, health problems and economic losses. The study aims at seeking universal approaches to the diagnostics, prevention and correction of burnout. The authors consider professional burnout as a combination of interdependent components: psychological, somatic and psychosomatic. In this case, it was necessary to study professional burnout and morbidity with temporal disability with due regard to age, sex, length of service and place of work, as well as to calculate the economic damage from the above-mentioned morbidity. They should also determine the significance of work experience and professional qualities in the formation of burnout and morbidity. To study professional burnout, the authors used proven, reliable and valid methods: diagnostic tests (questionnaire to reveal the emotional burnout degree by V.V. Boyko); questionnaire to measure professional burnout by K. Maslach and S. Jackson (abridged by N. E. Vodopianova). Morbidity with temporal disability and economic damage were considered with the help of statistical analysis, modeling and the PPP Statistica software. To determine professionally significant personality traits, the authors used the Wiesbaden questionnaire, cluster analysis using the Chebyshev similarity measure and the Kendall rank correlation coefficient to confirm the results of cluster analysis. The authors have compared the burnout of teachers working with gifted children with that experienced by rural teachers and doctors. They have identified age groups that are most susceptible to burnout and factors influencing the burnout of teachers.
\end{abstract}

\footnotetext{
* Corresponding author: a.golmenko@mail.ru
} 
Keywords: professional burnout; gifted children; teachers.

\section{Introduction}

Due to the existing research on the professional burnout of medical workers, we have decided to study the burnout of teachers, including teachers working with gifted children. The high burnout rate of doctors and teachers leads to a decrease in the quality of their work, staff turnover, health problems and economic losses.

Stress and burnout are common problems of public school teachers and are exacerbated in urban schools, where job requirements are often high and resources are limited. The stress and burnout of teachers are influenced by salary levels, professional self-efficacy, relationships with colleagues, students, resources, high workload, role conflicts, career adaptability, the lack of participation and social support [1-5].

The disruptive behavior of students during classroom activities can cause strong emotions in teachers and affect their professional well-being. Classes that were subject to 'intervention' (classroom management programs) demonstrated an improvement in students' behavior and academic performance if compared to control groups. Consequently, it is necessary to train young teachers $[6,7]$.

Some elements of stress and coping have an impact on current and future emotional exhaustion. Unlike stress, coping has demonstrated sensitivity to intervention effects [8].

The teacher's work requires self-control, which can lead to conflict between professional activity and personal life. It is still challenging to allocate time for research, training and performing office tasks. The study profile is associated with the least amount of homework $[9,10]$.

High-level workplace stress results in staff turnover. If teachers change, it entails economic, institutional and educational costs. Furthermore, it disrupts teamwork and undermines trust between institutions and families. The support of institutions softens the relationship between burnout and perceived internal competitiveness and career satisfaction $[11,12]$.

Engagement arises in the course of work and can change depending on a certain task. On the contrary, burnout is viewed as a chronic condition that develops over a long time and is associated with work rather than specific tasks [13].

Stressed out people are not just exhausted or overwhelmed by their workload, they lose a psychological connection with their work, which is important for one's motivation and personality [14].

The high workload is connected with burnout and symptoms of depression, which causes mental health problems and increases the duration of recovery $[15,16]$.

Burnout has adverse health and job consequences but there is no consensus on how to treat it. The intervention aims at increasing the psychological resources of employees and improving their ability to cope with stressors at work and home [2].

Close relationships with students and high personal achievements during the school year generated fewer conflicts and were associated with low emotional exhaustion [5].

Gifted students realize their full potential while satisfying the basic psychological needs for autonomy, competence and connection. The identification of potentially gifted children depends on the qualifications of teachers. The assessment criteria are mainly based on cognitive factors, including intelligence and achievement, but also such non-cognitive factors as motivation and creativity [17].

The descriptive nature, no unified understanding of this syndrome, the vagueness of the "burnout" concept, the lack of universal approaches to diagnostics, prevention and correction necessitates the search for new effective tools to solve this issue [18]. 
This study aims at considering the burnout of teachers and doctors, as well as determining the methods of diagnosis and prevention. We have studied professional burnout and morbidity with due regard to age, gender, the length of service and place of work, and calculated economic damages from morbidity.

We suggest that burnout should not be regarded as an independent phenomenon but rather as a combination of interdependent components: psychological, somatic and psychosomatic. The transition from adaptation to maladaptation is influenced by age, gender, length of service, place of work and personality traits.

The research objectives are as follows: to reveal the level of professional burnout typical of teachers working with gifted children; to determine the features, differences and similarities of the burnout of rural teachers and doctors; to provide age-related characteristics of burnout.

The further study should solve the following tasks: to assess the state of health and burnout as the interdependence of the above-mentioned components; to adapt the registered computer program "Assessing the professional and psychological suitability of medical workers" for school teachers; to calculate the economic damage from morbidity; to study the impact of social factors on burnout.

\section{Methods}

To study professional burnout, we used the reliable and valid methods developed by N.E. Vodopianova and V.V. Boyko [19]. Morbidity with temporal disability and economic damage were considered with the help of statistical analysis, modeling and the PPP Statistica software. To determine professionally significant personality traits, we used the Wiesbaden questionnaire, cluster analysis using the Chebyshev similarity measure and the Kendall rank correlation coefficient to confirm the results of cluster analysis.

\section{Results}

The professional burnout of lyceum teachers working with gifted children has a lot in common with that of medical workers but differs from the burnout of teachers in rural schools.

The reasons for the burnout of lyceum teachers are organizational shortcomings, conflicts, overload, dissatisfaction with work and, as a result, change of occupation.

In relation to lyceum teachers and rural teachers, emotional burnout in the phase of exhaustion is characterized by the following features: a decrease in sympathy, complicity, empathy, positive emotions, as well as an increase in harshness, rudeness and irritability. In this phase, lyceum teachers showed high rates of psychosomatic and psycho-vegetative disorders.

Lyceum teachers who work with gifted children mostly burn out in the first five years or after 20-25 years of work. After five years' experience, there is a decrease in burnout rates [20].

After 20-25 years of work, adaptation resources decrease, which results in professional and psychological maladaptation with a predominance of chronic morbidity.

The professional burnout of young medical employees showed that occupational work (the difference between general and medical experience) was $30 \%$. The optimal indicators of professionally significant personality traits reached $44 \%$ for medical personnel [21]. 


\section{Discussion}

The results obtained are consistent with the data provided by foreign scholars. Thus, we have revealed that burnout is influenced by organizational shortcomings, conflicts with colleagues, constant physical or psychological overload and job dissatisfaction. Stress and burnout lead to an increase in health problems and morbidity. As a result, burnout is viewed as a chronic condition that depends on the length of service.

In addition, foreign literature does not present any studies of burnout associated with the assessment of general and professional experience, professionally significant personality traits, the interdependence of both psychological and somatic components.

\section{Conclusion}

Burnout processes are influenced by the following factors: occupation, place of work, professional experience, age and personality traits. The limitations lie in the fact that the research results obtained on medical workers cannot be fully transferred to school teachers. There is a need for further research that should study the causes of professional burnout and prevent its development.

\section{References}

1. J.H. Bottiani, C.A.K. Duran, E.T. Pas, C.P. Bradshaw, Journal of School Psychology, 77, 36-51 (2019). https://doi.org/10.1016/j.jsp.2019.10.002

2. K. Ahola, S. Toppinen-Tanner, J. Seppänen, Burnout Research, 4, 1-11 (2017). https://doi.org/10.1016/j.burn.2017.02.001

3. W.-G. Tang, C. Vandenberghe, Journal of Vocational Behavior, 119, 103411 (2020). https://doi.org/10.1016/j.jvb.2020.103411

4. H. Xu, Journal of Vocational Behavior, 119, 103425 (2020). https://doi.org/10.1016/j.jvb.2020.103425

5. C.M. Corbin, P. Alamos, A.E. Lowenstein, J.T. Downer, J.L. Brown, Journal of School Psychology, 77, 1-12 (2019). https://doi.org/10.1016/j.jsp.2019.10.001

6. J.A. de Ruiter, A.M.G. Poorthuis, K. Aldrup, H.M.Y. Koomen, Journal of School Psychology, 82, 85-102 (2020). https://doi.org/10.1016/j.jsp.2020.08.005

7. P. Tolan, L.M. Elreda, C.P. Bradshaw, J.T. Downer, N. Ialongo, Journal of School Psychology, 78, 75-95 (2020). https://doi.org/10.1016/j.jsp.2019.12.002

8. C.L. Eddy, K.C. Herman, W.M. Reinke, Journal of School Psychology, 76, 17-32 (2019). https://doi.org/10.1016/j.jsp.2019.05.001

9. M.E. Clinton, N. Conway, J. Sturges, R. Hewett, Journal of Vocational Behavior, 118, 103410 (2020). https://doi.org/10.1016/j.jvb.2020.103410

10. K.A. French, T.D. Allen, M.H. Miller, E.S. Kim, G. Centeno, Journal of Vocational Behavior, 120, 103443 (2020). https://doi.org/10.1016/j.jvb.2020.103443

11. J. Kim, Y. Shin, E. Tsukayama, D. Park, Journal of School Psychology, 78, 13-22 (2020). https://doi.org/10.1016/j.jsp.2019.11.002

12. L. Barthauer, P. Kaucher, D. Spurk, S. Kauffeld, Journal of Vocational Behavior, 117, 103334 (2020). https://doi.org/10.1016/j.jvb.2019.103334

13. W. Schaufeli, H.D. Witte, Burnout Research, 5, 1-2 (2017). https://doi.org/10.1016/j.burn.2017.06.001 
14. M.P. Leiter, C. Maslach, Burnout Research, 3(4), 89-100 (2016). https://doi.org/10.1016/j.burn.2016.09.001

15. K. Upadyaya, M. Vartiainen, K. Salmela-Aro, Burnout Research, 3(4), 101-108 (2016). https://doi.org/10.1016/j.burn.2016.10.001

16. M.B. Kotova, V.B. Rozanov, A.A. Alexandrov, E.I. Ivanova, Voprosy Psikhologii, 2 , 67-79 (2017)

17. L. Hornstra, A. Bakx, S. Mathijssen, J.A. Denissen, Learning and Individual Differences, 80, 101871 (2020). https://doi.org/10.1016/j.lindif.2020.101871.

18. R.A. Bykov, E.Yu. Bykova, Yu.A. Vlasova, Sotsialnaya apatiya uchitelei kak forma adaptatsii k sovremennym sotsiokulturnym usloviyam [The social apathy of teachers as a kind of adaptation to modern sociocultural conditions] (Krasnoe znamya, Tomsk, 2020)

19. N.E. Vodopyanova, Psikhodiagnostika stressa [The psychological assessment of stress] (Piter, Saint Petersburg, 2009)

20. A.D. Golmenko, V.P. Ilyin, V.A. Haptanova, Somatic and psychological effects of occupational stress on medical staff, in Materials of the International Conference "Process Management and Scientific Developments", November 30, 2019, Birmingham, United Kingdom, 72-79 (2019).

https://doi.org/10.34660/INF.2019.2.42154

21. A.D. Golmenko, V.P. Ilyin, V.A. Haptanova, Methodological approaches to the diagnosis and assessment of professionally significant personal qualities of medical personnel, in Materials of the International Conference "Scientific research of the SCO countries: synergy and integration”, February 20, 2020. Beijing, PRC, 122-129 (2020). https://doi.org/10.34660/INF.2020.25.55689 